\title{
Antimicrobial prophylaxis in open lower extremity fractures
}

\author{
This article was published in the following Dove Press journal: \\ Open Access Emergency Medicine \\ 25 February 201I \\ Number of times this article has been viewed
}

\section{Amanda Anderson \\ April D Miller \\ P Brandon Bookstaver \\ Clinical Pharmacy and Outcomes Sciences, South Carolina College of Pharmacy, University of South Carolina, Columbia, SC, USA}

Date of preparation: November 2010.

Conflict of interest: PBB: Research grant support from Cubist Pharmaceuticals; Merck and Co., Inc.; Astellas US Pharma.
Correspondence: April D Miller South Carolina College of Pharmacy, University of South Carolina, 7I5 Sumter Street, Columbia, SC 29208, USA Tel 803-777-2265

Fax 803-777-2820

Email millerad@sccp.sc.edu
Clinical question: Based on the grade of open fracture, which antibiotic should be selected for antimicrobial prophylaxis, and what is the optimal timing and duration of administration?

Results: For Grade I and II open fractures, a first-generation cephalosporin (eg, cefazolin) should be administered within 3 hours of initial injury and be continued for 24 hours after initial injury. Grade III open fractures require coverage with an aminoglycoside in addition to a firstgeneration cephalosporin within 3 hours of initial injury, and antibiotics should be continued for 48-72 hours after initial injury but no more than 24 hours after wound closure. If a fracture is at risk of contamination with clostridium species, such as a farm-related injury, penicillin should be added to the antibiotic regimen.

Implementation: Pitfalls to avoid when using antibiotics for infection prophylaxis in open fractures include utilizing cultures immediately postinjury to direct choice of agent for antimicrobial prophylaxis, because infecting pathogens do not typically correlate to pathogens initially cultured after injury; failure to consider patients' medication allergy history or reconcile allergy records; and failure to obtain a thorough history to determine injury exposure (eg, farm, water).

Keywords: open fracture, penicillin, antibiotics, infection

Definition: An open fracture is one in which disruption of the skin and underlying soft tissues results in exposure of the wound to the outside environment. ${ }^{1}$ Fracture grade is determined according to the Gustilo classification system (Table 1). ${ }^{2}$ Antimicrobial prophylaxis is the use of antibiotics to prevent infection.

Incidence: According to a study conducted in the UK by Court-Brown et al, ${ }^{3}$ open fractures of long bones are estimated to occur at a rate of 11.5 per 100,000 people per year. Approximately $40 \%$ of these fractures involve the lower extremities, most commonly the tibia. Reported infection rates range from $0 \%$ to $9 \%$ for Grade I fractures, $1 \%$ to $12 \%$ for Grade II fractures, and $9 \%$ to $55 \%$ for Grade III fractures. ${ }^{4}$

Economics: There have been no published studies addressing the economic impact of infection in open fractures. These would need to include direct expenses related to hospital stay, surgical intervention, medication costs, and rehabilitation. In addition, indirect costs due to disability and missed work days would need to be taken into account, as well as relative costs of a subsequent infection.

Level of evidence: Randomized controlled trials, systematic reviews, practice guideline statements.

Search sources: PubMed, Cochrane Library, Ovid/MedLine, International Pharmaceutical Abstracts, Embase. 
Outcomes: From the clinician's perspective, the main outcomes of antimicrobial prophylaxis in open fractures are:

1. Prevention of infection

2. Promotion of or neutral effects on fracture healing

3. Restoration of limb function.
Consumer summary: A fracture is considered open when bone fragments break the skin and expose the wound to the outside environment. ${ }^{1}$ Evidence proves that in addition to appropriate wound cleansing, surgical removal of dead tissue, and stabilization of the wound, administration of antibiotics can minimize the risk of infection and improve outcomes. ${ }^{5}$

Table I Gustilo classification of open fractures ${ }^{2}$

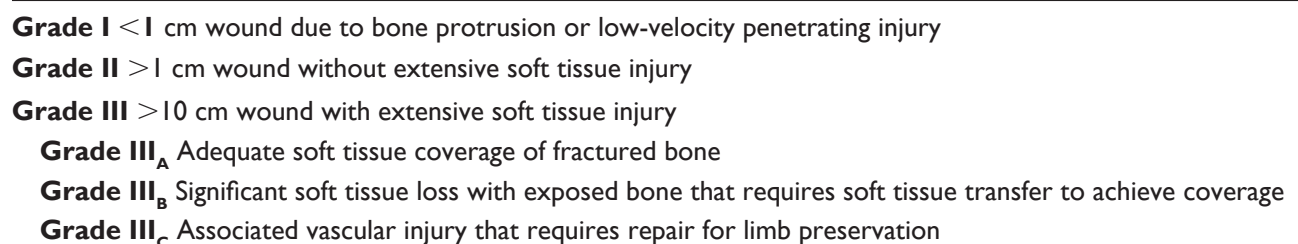

Adapted from Hoff WS, Bonadies JA, Cachecho R, Dorlac WC. EAST Practice Management Guidelines Work Group: update to practice management guidelines for prophylactic antibiotic use in open fractures; 2008.'

\section{The evidence}

\section{Based on fracture grade, which antibiotic(s) should be selected for antimicrobial prophylaxis?}

Systematic reviews:

Randomized controlled trials: 2

Practice guideline statements:

1

A systematic review by Hauser et $\mathrm{al}^{5}$ concluded that there are sufficient data for the use of a first-generation cephalosporin in Grade II and III open fractures for antimicrobial prophylaxis. Also, they concluded that there are insufficient data that antibiotics directed against Gramnegative bacilli or penicillin coverage for Clostridium species are beneficial as routine prophylaxis in any open fracture. The systematic review by Fletcher et $\mathrm{al}^{6}$ concluded that a firstgeneration cephalosporin should be used for all open fractures when not otherwise contraindicated, and aminoglycosides may decrease risk of infection in Grade II and III fractures. Also, there is inadequate evidence to support the use of penicillin for fractures with potential clostridial contamination.

Consensus practice guidelines ${ }^{1}$ concluded that systemic antibiotic coverage directed at Gram-positive organisms should be initiated in all open fractures. Additional Gram-negative coverage should be added for Grade III fractures, and penicillin should be added for fecal or possible clostridial contamination. Fluoroquinolones offer no advantage over the first-line regimen and may be detrimental in fracture healing. ${ }^{7}$ Antibiotics administered by the oral route have been studied, but there is insufficient evidence to recommend their routine use. ${ }^{1}$

\section{Based on fracture grade, what is the optimal timing and duration of antibiotic administration?}

$\begin{array}{ll}\text { Systematic reviews: } & 2 \\ \text { Randomized controlled trials: } & 2 \\ \text { Practice guideline statements: } & 1\end{array}$

A systematic review by Hauser et $\mathrm{al}^{5}$ concluded that for Grade II and III open fractures, administration of antibiotics for 48 hours perioperatively is safe and effective for antimicrobial prophylaxis. Routine prophylactic antibiotic use beyond the initial perioperative period is not beneficial in any open fracture. In a systematic review by Fletcher et al, ${ }^{6}$ antibiotic administration was recommended to be continued for 24 hours postoperatively.

A randomized controlled trial by Dellinger et $\mathrm{al}^{8}$ concluded that on presentation to the emergency department, 1-day antibiotic administration is equally efficacious as 5-day administration in preventing open fracture site infections.

A randomized controlled trial by Patzakis and Wilkins ${ }^{9}$ concluded that the early administration of antibiotics was the single most important factor in reducing the infection rate, which significantly increased when antibiotics were not initiated within 3 hours after injury.

Consensus practice guidelines ${ }^{1}$ concluded that for Grade I and II fractures, antibiotics should be discontinued 24 hours after wound closure; antibiotics for Grade III fractures should be continued for 72 hours following injury but not more than 24 hours after tissue coverage of the open wound. 


\section{Conclusions}

Grade I and II open fractures require coverage by a firstgeneration cephalosporin for 24 hours after wound closure. Grade III open fractures require coverage by a first-generation cephalosporin and an aminoglycoside for 48-72 hours after initial injury but no longer than 24 hours after wound closure If a fracture is at risk of contamination with Clostridium species, penicillin should be added to the antibiotic regimen. Antibiotics should be administered within 3 hours of initial injury, regardless of fracture grade.

\section{The practice}

\section{Potential pitfalls}

Pitfalls to avoid when using antibiotics for infection prophylaxis in open fractures:

- Utilizing cultures immediately postinjury to direct choice of agent for antimicrobial prophylaxis, because infecting pathogens do not typically correlate to pathogens initially cultured after injury

- Failure to consider patients' medication allergy history or to properly reconcile allergy records

- Failure to obtain a thorough history to determine injury exposure (eg, farm, water)

\section{Management}

Urgent management includes adequate debridement of devitalized tissue, copious irrigation with normal saline, and bone stabilization to decrease risk of infection and expedite patient rehabilitation. Antibiotic prophylaxis is intended as an adjunct to the standard operative management of open fractures. ${ }^{5}$

\section{Assessment}

- An open fracture is a traumatic injury most commonly resulting from a motor vehicle accident, fall, sportsrelated injury, or direct collision. ${ }^{10}$

- Management of open fractures differs according to the Gustilo classification (Table 1). ${ }^{2}$

\section{Treatment}

There is ample evidence supporting the use of antibiotics in the management of open fractures to prevent infection. ${ }^{1,6,11,12}$ However, there are conflicting data regarding the routine use of wound cultures, antibiotic selection according to fracture grade, timing of antibiotic administration, duration of antibiotic administration, and the value of locally administered antibiotics.

\section{Debridement cultures}

- Organisms contaminating open fracture wounds do not correlate to the pathogens responsible for infection.
Most infections of open fracture wounds result from nosocomial organisms.

- This is demonstrated in a study by Carsenti-Etesse et $\mathrm{al}^{4}$ which found that coagulase-negative Staphylococci, Bacillus spp., Acinetobacter spp., and Enterobacter spp. were the most common bacterial contaminants found in the fracture site on presentation to the emergency department and prior to surgery. However, cultures at the time of infection showed the most common Gram-positive organisms to be methicillin-sensitive and methicillin-resistant Staphylococcus aureus (MRSA), and Gram-negative organisms, including Enterobacter spp., Klebsiella spp., Escherichia coli, and Pseudomonas spp.

- Cultures immediately postinjury are not useful in directing antimicrobial prophylaxis.,

\section{Antibiotic selection}

- Antibiotic selection depends on the severity of the fracture and the environment in which the fracture occurred.

- Grade I and II open fractures are most likely to be infected with Gram-positive organisms (methicillin susceptible Staphylococcus aureus spp.). A first-generation cephalosporin (eg, cefazolin) should be administered. ${ }^{1}$

- Grade III open fractures are at greater risk of being infected with Gram-negative bacteria in addition to Gram-positive organisms. Antibiotic coverage should be expanded by adding an aminoglycoside, such as gentamicin, to the first-generation cephalosporin. ${ }^{1}$

- Vancomycin may be appropriate for first-line treatment if the patient has a significant, documented beta-lactam allergy, has a history of MRSA colonization, or is hospitalized in an area with recent MRSA outbreaks. ${ }^{6}$ Clinicians should also be cognizant of the associated risk for selection of resistant organisms such as MRSA that are associated with cephalosporins, particularly in patients who may require prolonged hospitalization. ${ }^{13}$

- For any fracture grade, in order to prevent infection by Clostridium species, Gram-positive anaerobic coverage 
with penicillin is necessary if the wound is contaminated with soil or feces, such as with farm-related injuries. ${ }^{1}$

- Because nosocomial organisms are typically responsible for deep surgical site infections, a study by Glass et $\mathrm{al}^{14}$ pertaining to the prevention of deep surgical site infections recommends an additional single dose of a prophylactic antibiotic with MRSA activity, such as vancomycin or teicoplanin, for Gustilo Grade IIIB fractures.

\section{Timing of antibiotic administration}

- Studies have consistently shown a definitive relationship between delay of antibiotic administration and increased risk of infection. ${ }^{9,11}$

- Antimicrobial prophylaxis should be started as soon as possible after the initial injury, specifically within 3 hours of initial injury, because risk of infection increases significantly beyond this period due to changes in circulation and multiplication of the bacteria. ${ }^{9}$

\section{Duration of antibiotic administration}

- Taking into account minimization of adverse events ${ }^{15,16}$ and risk of antimicrobial resistance, the evidence indicates that there is no clinical benefit to protracted courses of antibiotics. $^{8}$

- For Grade I and II fractures, antibiotics should be administered for 24 hours after wound closure. ${ }^{1}$

- For Grade III fractures, antibiotic administration should be continued for 48-72 hours after the initial injury but no more than 24 hours after wound closure. ${ }^{1}$

\section{Local antimicrobial prophylaxis}

- Local antibiotic-laden polymethylmethacrylate beads have been shown to produce high antibiotic concentrations at the site of injury while minimizing systemic exposure, thus decreasing the risk of systemic adverse effects. ${ }^{17}$

- Antibiotic drug candidates for local therapy should be heat stable, have a powder formulation, and be effective against common pathogens. ${ }^{17}$

- Local antibiotic therapy is not meant to replace systemic antibiotics but is a practical option for severe open fractures, specifically those with insufficient tissue for immediate wound closure. ${ }^{17}$

- In a study by Ostermann et $\mathrm{al}^{18}$ the infection rates for acute infection and/or chronic osteomyelitis in Grade I, II, and III open fractures was $3.7 \%$ for those utilizing systemic and local antibiotics compared with $12 \%$ with systemic antibiotics alone. This was only statistically significant for Grade III open fractures, reducing infection rates from $20.6 \%$ to $6.5 \%{ }^{18}$

\section{Indications for specialist referral}

- If the open fracture is associated with multitrauma motor vehicle accident injuries, management should include trauma specialists, including orthopedic and plastic surgeons.

- If the open fracture infection is secondary to a multidrugresistant pathogen, an infectious disease consult should be considered.

- Due to the altered pharmacokinetics in this patient population and the complex nature of the antibiotic pharmacodynamics, or in those patients with a significant allergy history, clinical pharmacist input for antibiotic selection and dosing should be considered.

\section{Further reading}

Hauser CJ, Charles AA, Soumitra RE. Prophylactic antibiotic use in open fractures: an evidence-based guideline. Surg Infect. 2006;7(4):379-405.

Hoff WS, Bonadies JA, Cachecho R, Dorlac WC. East Practice Management Guidelines Work Group: update to practice management guidelines for prophylactic antibiotic use in open fractures; 2008.

\section{References}

1. Hoff WS, Bonadies JA, Cachecho R, Dorlac WC. East Practice Management Guidelines Work Group: update to practice management guidelines for prophylactic antibiotic use in open fractures; 2008.

2. Gustilo RB, Mendoza RM, Williams DN. Problems in the management of type III (severe) open fractures: a new classification of type III open fractures. J Trauma. 1984;24(8):742-746.

3. Court-Brown CM, Rimmer S, Prakash U, McQueen MM. The epidemiology of open long bone fractures. Injury. 1998;29(7):529-534.

4. Carsenti-Etesse H, Doyon F, Desplaces N, et al. Epidemiology of bacterial infection during management of open leg fractures. Eur J Clin Microbiol Infect Dis. 1999;18:315-323.

5. Hauser CJ, Charles AA, Soumitra RE. Prophylactic antibiotic use in open fractures: an evidence-based guideline. Surg Infect. 2006;7(4):379-405.

6. Fletcher N, Sofianos D, Berkes MB, Obremskey WT. Prevention of perioperative infection. J Bone Joint Surg Am. 2007;89:1605-1618.

7. Huddleston PM, Steckelberg JM, Hanssen AD, et al. Ciprofloxacin inhibition of experimental fracture-healing. J Bone Joint Surg Am. 2000;82:161-173.

8. Dellinger EP, Caplan ES, Weaver LD, et al. Duration of preventive antibiotic administration for open extremity fractures. Arch Surg. 1988;123:333-339.

9. Patzakis MJ, Wilkins J. Factors influencing infection rate of open fracture wounds. Clin Orthop Relat Res. 1989;243:36-40.

10. Court-Brown CM, McBirnie J. The epidemiology of tibial fractures. J Bone Joint Surg Br. 1995;77:417-421.

11. Patzakis MJ, Harvey JP, Ivler D. The role of antibiotics in the management of open fractures. J Bone Joint Surg Am. 1974;56:532-541.

12. Brown KV, Walker JA, Cortez DS, et al. Earlier debridement and antibiotic administration decrease infection. J Surg Orthop Adv. 2010;19(1):18-22.

13. Dancer SJ. The problem with cephalosporins. JAntimicrob Chemother. 2001;48:463-478.

14. Glass GE, Barrett SP, Sanderson F, et al. The microbiological basis for a revised antibiotic regimen in high-energy tibial fractures: preventing deep infections by nosocomial organisms. J Plast Reconstr Aesthet Surg. 2010;doi:10.1016/j.bjps.2010.05.037. 
15. Harrahill M. Clostridium difficile colitis following an open fracture: complications occur, even with straightforward trauma and straight forward decisions. J Emerg Nurs. 2003;29:294-296.

16. Hoth JJ, Franklin GA, Stassen NA, et al. Prophylactic antibiotics adversely affect nosocomial pneumonia in trauma patients. J Trauma. 2003;55:249-254.
17. Melvin JS, Dombroski DG, Torbert JT, et al. Open tibial shaft fractures: I. Evaluation and initial wound management. J Am Acad Orthop Surg. 2010;18:10-19.

18. Ostermann PAW, Seligson D, Henry S. Local antibiotic therapy for severe open fractures. J Bone Joint Surgery [Br]. 1995;77-B:93-97.

Open Access Emergency Medicine

\section{Publish your work in this journal}

Open Access Emergency Medicine is an international, peer-reviewed, open access journal publishing original research, reports, editorials, reviews and commentaries on all aspects of emergency medicine. The manuscript management system is completely online and includes a very quick and fair peer-review system, which is all easy to use.

\section{Dovepress}

Visit http://www.dovepress.com/testimonials.php to read real quotes from published authors. 